\title{
Rapunzel Syndrome Reviewed and Redefined
}

\author{
Saleem Naik ${ }^{\mathrm{a}, \mathrm{e}}$ Vivek Gupta $^{\mathrm{a}}$ Swati Naik $^{\mathrm{b}}$ Ashwin Rangole \\ Ashok K. Chaudhary ${ }^{d}$ Prashant Jain $^{a}$ Ashok K. Sharma ${ }^{a}$

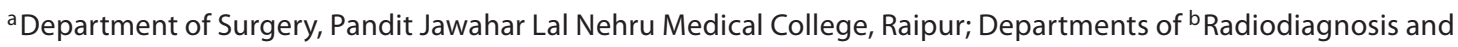

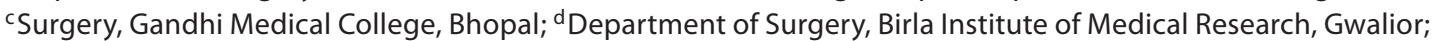 \\ and ${ }^{\text {eDepartment }}$ of Surgical Gastroenterology, Bhopal Memorial Hospital, Bhopal, India
}

\section{Key Words}

Bezoar $\cdot$ Rapunzel syndrome $\cdot$ Trichobezoar .

Trichotillomania $\cdot$ Intestinal obstruction

\begin{abstract}
Rapunzel syndrome is a rare presentation of a trichobezoar, with 24 cases having been reported in literature so far. This syndrome has been reported in 23 female and 1 male patient with a mean age of 10.8 years. The patients commonly present with abdominal pain, nausea, vomiting and signs of obstruction. The distal end of the bezoar may be in the jejunum, ileum or the colon. We evaluate the various cases reported and discuss the various modes of presentation of this uncommon syndrome, and also present a series of 3 cases, all females, aged 16, 18 and 21 years, and had a trichobezoar in the stomach with a tail extending into the ileum.
\end{abstract}

Copyright $\odot 2007$ S. Karger AG, Base

\section{Introduction}

Trichotillomania, i.e., the irresistible desire to pull out ones own hair, was first described in 1889 by Hallopeau, while the first case of a trichobezoar was reported a century earlier by Baudamant in 1779 [1]. Trichobezoars are usually without symptom until they reach a large size. Rapunzel syndrome is a rare form of trichobezoar, Vaughan et al. [2] first described this syndrome in 1968 in 2 patients. Though Vaughan et al. [2] did not give any strict definitions of the syndrome, both their patients had a trichobezoar with a tail-like extension and symptoms of obstruction. We report 3 cases with similar features.

\section{Case Reports}

Case 1

A 16-year-old female presented with a history of anorexia and occasional vomiting. Clinical examination revealed a mobile lump in the abdomen in the shape of a dilated stomach. She had a history of recurrent admissions for subacute intestinal obstruction. Her blood picture revealed hypochromic microcytic anemia. Barium contrast showed an intragastric mass with barium in the honeycomb interstices (fig. 1). The barium contrast outlined the margins of the mass and penetrated the interstices in a lace-like 'mottled' pattern. There was no connection to the stomach wall and the mass did not arise from it.

On laparotomy a large gastric trichobezoar was present. It had a tapering tail, which extended into the proximal ileum (tail length $116 \mathrm{~cm}$; fig. 2a). The mass was removed by gastrostomy. The patient made an uneventful recovery. On retrospective questioning the patient denied trichophagia but her parents remarked that they had often seen her putting hairballs in her mouth.

\section{KARGER}

Fax +41613061234 E-Mail karger@karger.ch www.karger.com
(C) 2007 S. Karger AG, Basel

0253-4886/07/0243-0157\$23.50/0

Accessible online at:

www.karger.com/dsu
Saleem Naik

Department of Surgical Gastroenterology

Bhopal Memorial Hospital and Research Centre

Bhopal, Madhya Pradesh 462038 (India)

Tel. +91 755274 2212, ext. 1102, Fax +91 755274 8309, E-Mail saleemnaik@yahoo.com 


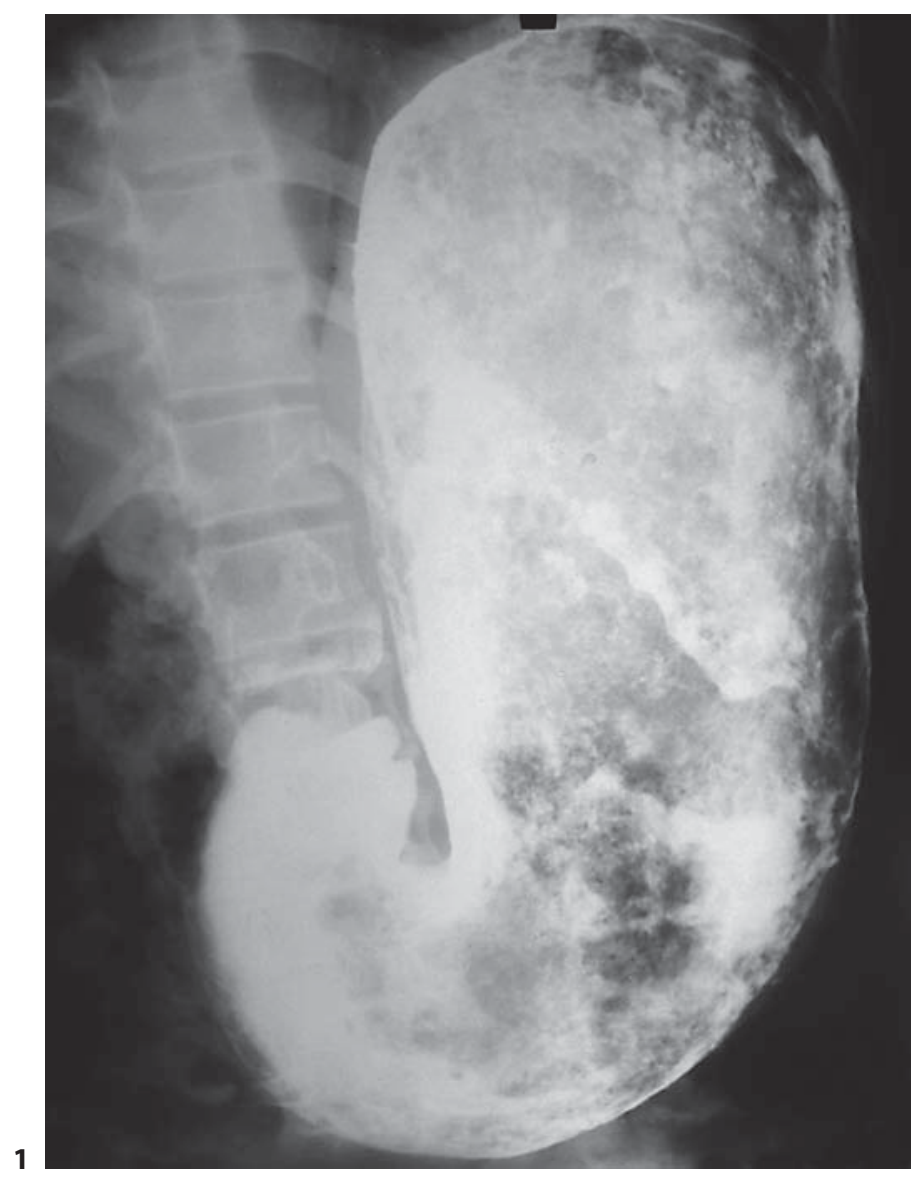

Fig. 1. Barium contrast study showing an intragastric trichobezoar.

Fig. 2. Post-surgical specimens of case 1 (a), case 2 (b), and case 3 (c).

Case 2

A 18-year-old female presented with complaints of abdominal distension, pain in the abdomen and vomiting of 4 days duration. On examination she had tachycardia and abdominal distension with exaggerated bowel sounds. Plain radiograph of the abdomen showed multiple air fluid levels with dilated small intestine loops. Conservative management with fluids and nasogastric aspiration for $24 \mathrm{~h}$ failed to improve her clinical condition. She was subsequently explored and a trichobezoar was found in the antrum extending into duodenum and proximal jejunum. This was removed by gastrostomy. The distal small bowel had another trichobezoar which was the cause of the obstruction and was removed by a separate enterotomy (fig. 2b). Part of the distal small bowel was gangrenous with multiple impending perforations. It was resected and an end-to-end ileoileal anastomosis was performed. The patient recovered uneventfully and was discharged on the 10 th postoperative day. On retrospective questioning she admitted having trichophagia and trichotillomania.
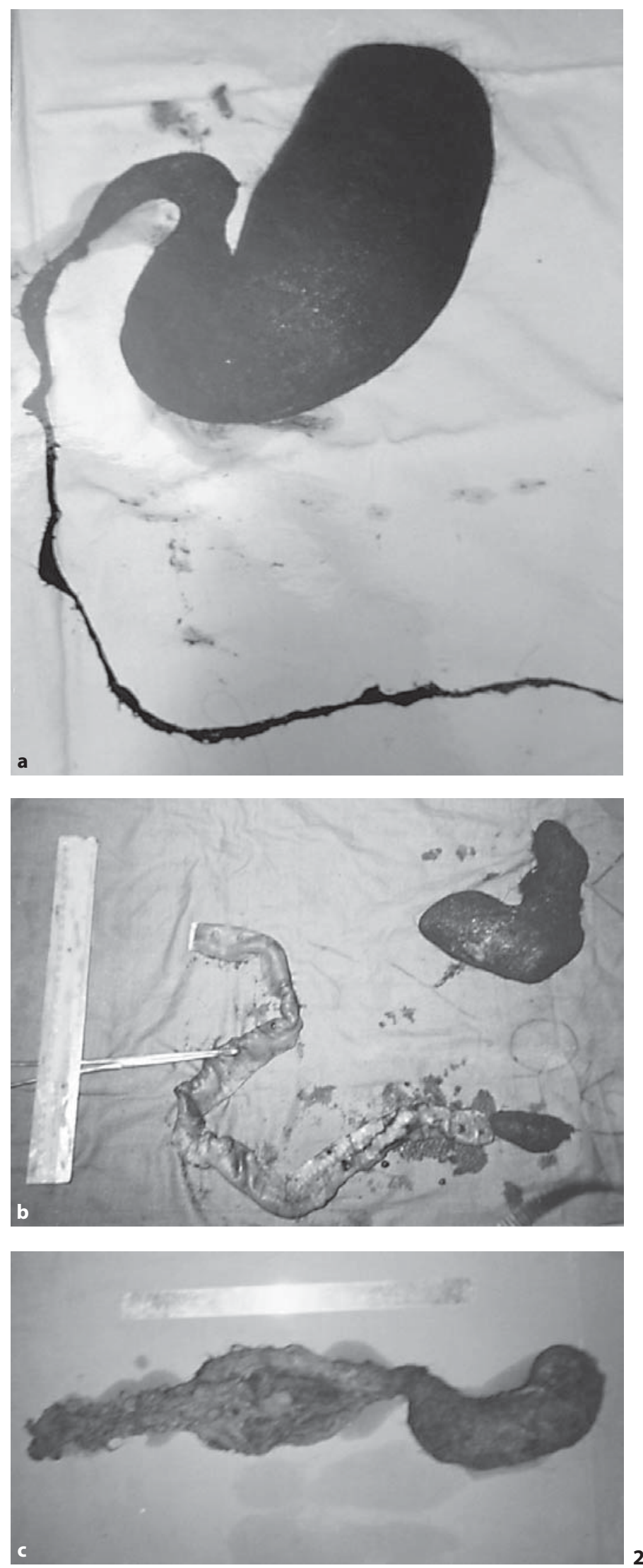
Table 1. Rapunzel syndrome: cases reported and their characteristics

\begin{tabular}{|c|c|c|c|c|c|c|c|}
\hline & Author & Year & Age & Sex & Presentation & Extent & Outcome \\
\hline 1 & Vaughan et al. [2] & 1968 & 13 & $\mathrm{~F}$ & Peritonitis & Jejunum to ileocecal valve & Alive \\
\hline 2 & Vaughan et al. [2] & 1968 & 15 & $\mathrm{~F}$ & Obstruction & Jejunum to colon & Alive \\
\hline 3 & Deslypere et al. [5] & 1982 & 14 & $\mathrm{~F}$ & Nausea + vomiting & Stomach to transverse colon & Died \\
\hline 4 & Buyukunal et al. [10] & 1982 & 5 & $\mathrm{~F}$ & Sepsis & Details not available & Died \\
\hline 5 & Wolfson et al. [11] & 1987 & 5 & $\mathrm{~F}$ & Volvolus & Stomach to cecum & Alive \\
\hline 6 & Hassan and Panesar [12] & 1989 & 5 & $\mathrm{~F}$ & Weight loss & Stomach to ileocecal valve & Alive \\
\hline 7 & Balik et al. [9] & 1982 & 15 & $\mathrm{~F}$ & $\begin{array}{l}\text { Abdominal pain, } \\
\text { bilious vomiting }\end{array}$ & $\begin{array}{l}\text { Stomach to jejunum } \\
(53 \mathrm{~cm} \text { tail })\end{array}$ & Alive \\
\hline 8 & Duncan et al. [13] & 1993 & 5 & $\mathrm{~F}$ & Intussusception & Stomach to ileocecal valve & Alive \\
\hline 9 & Uroz Tristan et al. [14] & 1996 & 8 & $\mathrm{~F}$ & vomiting + asthenia & Stomach to jejunum & \\
\hline 10 & Pul and Pul [15] & 1996 & 12 & $\mathrm{~F}$ & Vomiting distension anorexia & Stomach to ileocecal valve & Alive \\
\hline 11 & Seker et al. [16] & 1996 & 6 & $\mathrm{~F}$ & Obstruction & Stomach to cecum & Alive \\
\hline 12 & $\begin{array}{l}\text { Senapati and } \\
\text { Subramanium [17] }\end{array}$ & 1997 & 8 & $\mathrm{~F}$ & Pain + hematemesis & $\begin{array}{l}\text { Stomach to jejunum } \\
(20 \mathrm{~cm} \text { tail })\end{array}$ & Alive \\
\hline 13 & Dalshaug et al. [18] & 1999 & 7 & $\mathrm{~F}$ & $\begin{array}{l}\text { Intussusception } \\
+ \text { obstruction }\end{array}$ & $\begin{array}{l}\text { Mid jejunum to transverse } \\
\text { colon }\end{array}$ & Alive \\
\hline 14 & Singla et al. [19] & 1999 & 9 & $\mathrm{~F}$ & Weight loss + abdominal pain & Stomach to ileum & Alive \\
\hline 15 & Kasparet al. [20] & 1999 & 12 & $\mathrm{~F}$ & Obstruction & Stomach to ileum & Alive \\
\hline 16 & Faria et al. [1] & 2000 & 7 & $\mathrm{~F}$ & Peritonitis & Stomach to ? (not detailed) & \\
\hline 17 & Hirugade et al. [21] & 2001 & 6 & M & Colic + vomiting & $\begin{array}{l}\text { Stomach to terminal ileum } \\
(195 \mathrm{~cm} \text { tail })\end{array}$ & Alive \\
\hline 18 & Couper $[22]$ & 2001 & 4 & $\mathrm{~F}$ & Epigastric pain & Stomach to jejunum & Alive \\
\hline 19 & Curosio Vilchez et al. [23] & 2002 & 22 & $\mathrm{~F}$ & Details not available & Details not available & \\
\hline 20 & Klipfel et al. [24] & 2003 & 14 & $\mathrm{~F}$ & $\begin{array}{l}\text { Vomiting gastric } \\
\text { emphysema }\end{array}$ & $\begin{array}{l}\text { Stomach separate in terminal } \\
\text { ileum }\end{array}$ & Alive \\
\hline 21 & Memon et al. [25] & 2003 & 10 and 12 & $\mathrm{~F}$ & Nausea + colic & Stomach to proximal ileum & Alive \\
\hline 22 & Gockel et al. [26] & 2003 & 4 & $\mathrm{~F}$ & Abdominal pain & Details not available & Alive \\
\hline 23 & Deevaguntla et al. [27] & 2004 & 12 & $\mathrm{~F}$ & Pain, vomiting & Stomach to distal small bowel & Alive \\
\hline 24 & Eryilmaz et al. [28] & 2004 & 19 & $\mathrm{~F}$ & Pain, vomiting & Stomach to? (not detailed) & Alive \\
\hline 25 & Naik et al. [present study] & 2006 & 16 & $\mathrm{~F}$ & Pain, SAIO & Stomach to ileum & Alive \\
\hline 26 & Naik et al. [present study] & 2006 & 18 & $\mathrm{~F}$ & Peritonitis & Stomach to mid ileum & Alive \\
\hline 27 & Naik et al. [present study] & 2006 & 21 & $\mathrm{~F}$ & Peritonitis & Stomach to terminal ileum & Alive \\
\hline
\end{tabular}

SAIO = Subacute intestinal obstruction.

Case 3

A 21-year-old female presented with repeated episodes of pain and distension of the abdomen, and vomiting of 6 days duration. On examination her abdomen was distended and bowel sounds were exaggerated. Plain radiograph of the abdomen showed multiple fluid levels and dilated small intestinal loops suggestive of small gut obstruction. She was managed conservatively and improved. Enteroclysis was advised but the patient was lost to follow-up. She presented 2 months later with peritonitis and the abdominal X-ray showed free gas under the diaphragm. On exploration there was contamination of the peritoneum with ileal content. Intussusception of the small gut was present at multiple places. A trichobezoar, which extended through the whole length of the small gut, was seen in the stomach. The length of the hair was less than the length of the small bowel and hence it was causing a pursestring-like effect. Peristaltic tightening of the strong, wire-like, twisted hairs of the 'tail' of the bezoar had caused con- traction and compression of the mesenteric aspect of the wall of small bowel.

Gastrostomy was performed along with multiple enterotomies and the entire mass was removed (fig. 2c). The perforated bowel was resected and an ileostomy was made about $0.9 \mathrm{~m}$ proximal to the ileocecal junction. She had an uneventful postoperative course and was discharged 32 days after surgery. She admitted having trichophagia but denied trichotillomania.

\section{Discussion}

Trichobezoars are commonly found in young females usually with an underlying psychiatric disorder [3]. Formation of trichobezoars occurs when the hair strands are 
Table 2. Rapunzel syndrome: summary of cases reported and their characteristics

\begin{tabular}{lc}
\hline Total patients & 27 \\
\hline Demographics & \\
Mean age, years & 10.8 \\
$\quad$ Range & $4-22$ \\
Sex & \\
$\quad$ Male & 1 \\
$\quad$ Female & 26 \\
\hline Presenting symptoms & \\
Abdominal pain, \% & 37.0 \\
Peritonitis, \% & 18.5 \\
Nausea and vomiting, \% & 33.3 \\
Obstruction, \% & 25.9 \\
Weight loss, \% & 7.4 \\
Intussusception, \% & 7.4 \\
\hline Bezoar length & \\
Stomach to jejunum, \% & 14.4 \\
Stomach to ileum, \% & 25.9 \\
Stomach to colon, \% & 25.9 \\
Jejunum to colon, \% & 11.6 \\
Unknown, \% & 22.2 \\
\hline
\end{tabular}

retained in the folds of the gastric mucosa because their slippery surface prevents propulsion by peristalsis. As more hair is added, peristalsis causes it to be enmeshed until a ball, too large to leave the stomach, forms causing gastric atony due to its large size. This large quantity of hair becomes matted together and assumes the shape of the stomach, usually as a single mass $[4,5]$.

The increased incidence of these casts forming in the stomach is probably because of the initial hold up by the pylorus, and the churning action of the stomach which helps entangle new hair into the already formed casts.

The mucus covering the bezoar gives it a glistening shiny surface. Decomposition and fermentation of fats in the interstices gives it a putrid smell [6]. The acidic contents of the stomach denature the hair protein giving it its black color regardless of the original color of the hair $[7,8]$.

\section{Rapunzel Syndrome}

Rapunzel syndrome is a rare form of trichobezoar. It is named after a charming tale written in 1812 by the Brothers Grimm about a young maiden, Rapunzel, with long tresses [2] who lowered her hair to the ground from high in her prison tower to permit her young prince to climb up to her window and rescue her.
This syndrome was originally described by Vaughan et al. [2] in 1968. Since then 27 cases have been reported in the literature, with variable clinical features (table 1). Various criteria have been used by different clinicians to report their cases as Rapunzel syndrome. Some have defined it as a gastric trichobezoar with a tail extending up to the ileocecal junction [20]; others have said it is simply a trichobezoar with a long tail, which may extend to the jejunum, ileum or the ileocecal junction, and still others have defined it as a trichobezoar of any size which presents in the form of an intestinal obstruction [1]. The cases reported to date and their differing clinical and anatomical characteristics are summarized in table 2 .

The identical features which would thus qualify all these cases to be a Rapunzel syndrome are: (1) a trichobezoar with a tail; (2) extension of the tail at least to the jejunum, and (3) symptoms suggestive of obstruction.

All the cases reported in the literature are females, except one. This may be attributed to the traditional long hair of females which makes them more prone to entanglement and hence formation of trichobezoar casts. The only male was reported by Hirugade et al. [21]. This patient, however, ate the hair of his sisters.

Most of the cases have been reported in countries where women traditionally have long hair. The most common presenting features are abdominal pain (37\%), nausea and vomiting (33.3\%), obstruction (25.9\%), and peritonitis (18.3\%). Uncommonly though, patients have also presented with weight loss (7.4\%), anorexia, hematemesis and intussusception (7.4\%; table 2). Most of the patients deny any history of trichotillomania or trichophagia, even when specifically asked. A thorough psychiatric evaluation and management are hence advocated. Conservatively managed cases have had a poor outcome and hence surgical removal is advised whenever preoperative diagnosis is made. However, most cases are diagnosed at laparotomy. Surgical removal is advocated by gastrostomy and enterotomies when required. Three recurrences have been reported [13, 25, 28]. In 2 cases, the first episode was as a simple trichobezoar and the subsequent episode presented as Rapunzel syndrome, and in 1 case both the initial and the recurrent presentation was as Rapunzel syndrome [25]. Hence a long-term psychiatric follow-up is advised. A follow-up endoscopy or contrast study may also be advised if trichotillomania is suspected, as the patient usually never gives a positive history. Many of these patients report having parental discontent $[1,13]$, bereavement [13], or other family problems [26]. Parental or spouse counseling is also be advised as a regular part of treatment to prevent recurrence. 


\section{Conclusion}

Rapunzel syndrome is an uncommon trichobezoar, with a tail extending into the small intestine. It has a varied presentation and is seldom diagnosed preoperatively.
Management requires gastrostomy and enterotomies, when required. A psychiatric assessment and a longterm follow-up are advocated with parental or spouse counseling as a regular part of treatment to prevent recurrence.

\section{References}

1 Faria AP, Silva IZ, Santos A, Avilla SGA, Silveria AE: The Rapunzel syndrome - a case report: trichobezoar as a cause of intestinal perforation (in Portuguese). J Pediatria (Rio J) 2000;76:83-86.

-2 Vaughan ED Jr, Sawyers JL, Scott HW Jr: The Rapunzel syndrome. An unusual complication of intestinal bezoar. Surgery 1968;63: 339-343.

3 Phillips MR, Zaheer S, Drugas GT: Gastric trichobezoar: case report and literature re view. Mayo Clin Proc 1998;73:653-656.

4 Pace AP, Fearne C: Trichobezoar in a 13 year old male: a case report and review of literature, Malta Med J 2003;15:39-40.

$\checkmark 5$ Deslypere JP, Praet M, Verdonk G: An unusual case of trichobezoar: the Rapunzel syndrome. Am J Gastroenterol 1982;77:467470.

6 Sidhu BS, Singh G, Khanna S: Trichobezoar. J Indian Med Assoc 1993;91:100-101.

7 Sharma V: Gastrointestinal bezoars. J Indian Med Assoc 1991;89:338-339.

$\checkmark 8$ O'Sullivan MJ, McGreal G, Walsh JG: Trichobezoar. J R Soc Med 2001;94:68-70.

$\checkmark 9$ Balik E, Ulman I, Taneli C, Demirican M: The Rapunzel syndrome: a case report and review of literature. Eur J Pediatr Surg 1993; 3:171-173.

10 Buyukunal C, Seynuz OF, Soylet Y, Danismend N, Alver O: Rapunzel syndrome olgusu. Cerrahpasa Tip Fak Der 1982;13:142147.
Wolfson PJ, Fabius RJ, Leibowitz AN: The Rapunzel syndrome: an unusual trichobezoar. Am J Gastroenterol 1987;82:365-367.

12 Hassan AA, Panesar KJ: The Rapunzel syndrome: a rare presentation of trichobezoar. Ulster Med J 1989;58:94-96.

13 Duncan ND, Aitken R, Venugopal S, et al: The Rapunzel syndrome. Report of a case and review of the literature. West Indian Med J 1994;43:63-65.

14 Uroz Tristan J, Garcia Urgelles X, Melian Perez-Marin S: Rapunzel syndrome: a report of a new case (in Spanish). Cir Pediatr 1996; 9:40-41.

15 Pul N, Pul M: The Rapunzel syndrome (trichobezoar) causing gastric perforation in a child: a case report. Eur J Pediatr 1996;155: 18-19.

16 Seker B, Dilek ON, Karaayvaz M: Trichobezoars as a cause of gastrointestinal obstructions: the Rapunzel syndrome. Acta Gastroenterol Belg 1996;59:166-167.

-17 Senapati MK, Subramanium S: Rapunzel syndrome. Trop Doct 1997;27:53-54.

18 Dalshaug GB, Wainer S, Hollaar GL: The Rapunzel syndrome (trichobezoar) causing atypical intussusception in a child: a case report. J Pediatr Surg 1999;34:479-480.

19 Singla SL, Rattan KN, Kaushik N, Pandit SK: Rapunzel syndrome - a case report. Am J Gastroenterol 1999;94:1970-1971.

20 Kaspar A, Deeg KH, Schmidt K, Meister R: Das Rapunzel-Syndrom, eine ungewöhnliche Form intestinaler Trichobezoare. Klin Pädiatr 1999;211:420-422.
21 Hirugade ST, Talpallikar MC, Deshpande AV, Gavali JS, Borwankar SS: Rapunzel syndrome with a long tail. Indian J Pediatr Surg 2001;68:895-896.

22 Couper RTL: Clinical picture: Rapunzel syndrome. Lancet 2001;358:1304.

23 Curioso Vilchez WH, Rivera Vega J, Curioso Abriojo WI: Rapunzel syndrome: case report and literature review. Rev Gastroenterol Peru 2002;22:168-172.

24 Klipfel AA, Kessler E, Schein M: Rapunzel syndrome causing gastric emphysema and small bowel obstruction. Surgery 2003;133: 120-121.

25 Memon SA, Mandhan P, Qureshi JN, Shairani AJ: Recurrent Rapunzel syndrome - a case report. Med Sci Monit 2003;9:CS92CS94.

26 Gockel I, Gaedertz C, Hain HJ, Winckelmann, Albani M, Lorenz D: The Rapunzel syndrome: rare manifestation of trichobezoar of upper gastrointestinal tract (in German). Chirurg 2003;74:753-756.

27 Deevaguntla CR, Prabhakar B, Prasad GR: Rapunzel syndrome - a case report. J Indian Assoc Pediatr Surg 2004;9:33-34.

28 Eryilmaz R, Sahin M, Alimoglu O, Yildiz MK: A case of Rapunzel syndrome (in Turkish). Ulus Travma Acil Cerrahi Derg 2004; 10:260-263. 